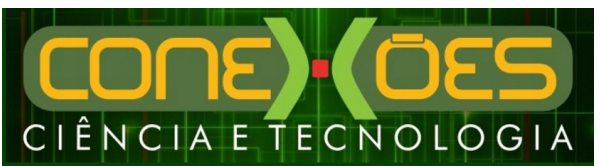

POTÊNCIA EÓLICA INSTALADA NO ESTADO DO CEARÁ E IMPACTO EM SUA MATRIZ ENERGÉTICA

\title{
POTÊNCIA EÓLICA INSTALADA NO ESTADO DO CEARÁ E IMPACTO EM SUA MATRIZ ENERGÉTICA
}

\author{
Henrique do Nascimento CAmelo ${ }^{1}$, Ariane Eduarda Vasconcelos ${ }^{1}$, \\ PAulo SÉrgio LuCiO ${ }^{2}$,Jõ̃o Bosco VerÇOSA LEAL Junior ${ }^{3}$
}

\author{
${ }^{1}$ Instituto Federal de Educação, Ciência e Tecnologia do Ceará - IFCE, campus de Acaraú \\ ${ }^{2}$ Universidade Federal do Rio Grande do Norte - UFRN, Programa de Pós-graduação em Ciências Climáticas \\ ${ }^{3}$ Universidade Estadual do Ceará - UECE, Mestrado Acadêmico em Ciências Físicas Aplicadas \\ <henriquecamelo13@yahoo.com.br>,<arianeeduardavasconcelos@gmail.com> \\ <pslucio@ccet.ufrn.br>.<jblealjr@uece.br>
}

DOI: $10.21439 /$ conexoes.v11i3.846

\begin{abstract}
Resumo. Esse trabalho tem como objetivo apresentar o crescimento da potencia eólica instalada no estado do Ceará-Brasil, desde seus primórdios até os dias atuais e também identificar impactos em sua matriz energética. Nesse estudo além de apresentar levantamentos bibliográficos a respeito da implantação de parques eólicos no estado do Ceará e seu impacto na matriz energética, será discutido com base em estudos teóricos a respeito da importância da energia eólica, além de utilizar referências de relatórios e de dados divulgados por empresas como à CERNE, a ANEEL, o PROINFA, a ABEEOLICA e outros órgãos. Atualmente o país tem $6 \mathrm{GW}$ de potencia eólica instalada contabilizando uma participação de 4,5\% na matriz energética nacional com 241 parques eólicos em funcionamento. O estado do Ceará não fica atrás nessa produção, pois o mesmo é um dos líderes no ranking de produção eólica no país, essa colocação se deve ao funcionamento de 59 parques eólicos que contribuem para essa porcentagem de energia utilizada. O crescimento do potencial eólico do Ceará ocorre por ter uma localização privilegiada, o que faz com que atualmente a energia elétrica utilizada no estado conte com mais de $57 \%$ do seu valor decorrente da energia eólica. A fonte proveniente dos ventos passou de $5 \mathrm{MW}$ em 1992 para 1,23 GW em 2015, suficiente para abastecer 2,9 milhões de domicílios consumindo cerca de $120 \mathrm{~kW} / \mathrm{h}$. De acordo com pesquisas com os constantes investimentos nesse setor o estado conseguirá atingir em 2016 1,8 GW de potencia instalada, que pode ser atingido antes do previsto devido ao período de estiagem.
\end{abstract}

Palavras-chaves: Potencial Eólico, Desenvolvimento Sustentável, Ceará, Matriz Energética.

\begin{abstract}
This work aims to present the growth of wind power installed in the state of Ceará, Brazil, from its beginnings to the present day and to identify impacts on its energy mix. This study besides presenting literature surveys concerning the deployment of wind farms in the state of Ceará and its impact on the energy matrix, will be discussed based on theoretical studies about the importance of wind energy, and use published reports references and data by companies like the CERNE, ANEEL, PROINFA, the ABEEOLICA and other organs. Currently the country has $6 \mathrm{GW}$ of installed wind power accounting for a share of $4.5 \%$ in the national energy matrix with 241 wind farms in operation. The state of Ceará is not far behind in this production, because it is one of the leading wind power ranking in the country, this place is due to the operation of 59 wind farms that contribute to this percentage of energy used. The growth of the wind potential of Ceará is to have a privileged location, which means that currently the electricity used in the state has more than $57 \%$ of its value due to the wind. The source from the winds went from $5 \mathrm{MW}$ in 1992 to $1.23 \mathrm{GW}$ in 2015, enough to supply 2.9 million households consuming about $120 \mathrm{~kW} / \mathrm{h}$. According to surveys with constant investments in this sector will achieve the state in 2016 installed capacity of $1.8 \mathrm{GW}$, which can be achieved ahead of schedule due to the dry season.
\end{abstract}

Keywords: Wind Potential, Sustainable Development, Ceará, Energy Matrix. 


\section{INTRODUÇÃO}

A situação ambiental atual busca fontes renováveis visando um desenvolvimento sustentável associado ao crescimento tecnológico. A expressão "desenvolvimento sustentável" é hoje um dos termos mais conhecidos no Brasil e no mundo, onde conferencias e debates procuram aliar a natureza ao crescimento e desenvolvimento mundial. (SILVA, 2013). Muitas dessas conferências são realizadas pela Organização das Nações Unidas (ONU) onde o debate ambiental tem grande importância. A sociedade atual colabora com a alta nos preços de combustíveis fosseis devido a problemas sociais e políticos nas regiões responsáveis pela produção dos mesmos e ao esgotamento das reservas de petróleo, impulsionando um crescimento no consumo energético e aumentando a preocupação com a situação ambiental. A questão energética trabalha lado a lado com o desenvolvimento sustentável, buscando fontes limpas de energia, pois visa unir a natureza e o desenvolvimento mundial.

As mudanças climáticas decorrentes das emissões dos gases de efeito estufa apontam uma crise ambiental em escala mundial sem precedentes (BERMANN, 2008). Fatores ambientais também podem reduzir a segurança energética como, por exemplo, a ocorrência de longos períodos de estiagem que afetam a produtividade da biomassa e a geração hidroelétrica (MARTINS, GUARNIERI e PEREIRA, 2008). Visando menor impacto ambiental ao meio ambiente como forma de desenvolvimento sustentável o Brasil é um dos países que vem se destacando no setor energético alternativo mundial. Uma das fontes limpas que vem ganhando espaço é a energia proveniente dos ventos. As fontes renováveis, em especial a eólica, se mostram atrativas, tanto pelo caráter não poluente quanto por se apresentarem como uma fonte inesgotável de energia (CUSTÓDIO 2009).

O Brasil busca tornar limpa a energia produzida no país ampliando seu cenário energético. A energia eólica vem apresentando um crescimento significativo de potência instalada, pois a mesma é uma das fontes energéticas limpa mais extraída no país, principalmente no Nordeste. Dentre os estados o Ceará é atualmente segundo no ranking de geração eólica nacional, com produção expressiva na matriz energética. $\mathrm{O}$ estado conta com parques eólicos em funcionamento, que impulsionam a economia com a geração de empregos, com a redução de gases que contribuem para o efeito estufa e com o desenvolvimento sustentável.

O Ceará demonstrou interesse e realizou estudos do seu potencial eólico, desde a implantação da primeira torre eólica no país. Muitas pesquisas e trabalhos são realizados sobre o potencial eólico do estado, onde os mesmos destacam o potencial eólico cearense. Além de toda essa análise sobre a produção eólica no estado os trabalhos mostram que algumas cidades e regiões do Ceará poderiam ser estudadas e exploradas para a geração eólica. Porém, a implantação de parques no Ceará vem acontecendo apenas na área costeira do estado, gerando assim uma concentração que ocasiona o desconforto por parte da população e maximizam impactos como o visual (CARVALHO et al., 2012). Esse desconforto é devido à destruição de praias, vegetação local, entre outros impactos provocados na natureza local e nas comunidades que vivem na mesma. É de extrema importância o uso de energias alternativas, contudo é necessário que elas sejam utilizadas de maneira adequada, sem causar impactos as áreas de preservação permanente e às comunidades que vivem nesses locais (FREITAS, 2014).

Os parques são implantados em sua maioria em cidades costeiras pelo favorecimento dos bons ventos do local e acabam por tirar parte da beleza natural dos mesmos. Cabe ressaltar que é importante reconhecer que a velocidade média dos ventos na faixa litorânea é maior durante o período sem chuvas e decai durante o período chuvoso, se igualando as regiões serranas e do sertão, que durante o ano a velocidade dos ventos pouco muda. Todos os trabalhos já realizados têm por objetivo apresentar a capacidade eólica do estado devido sua localização territorial e seu clima predominante.

O estado do Ceará é um importante produtor de energia eólica, que chega a pôr na matriz energética estadual o equivalente a mais de $57 \%$ da energia consumida no estado. O estado que começou com apenas um parque eólico implantado no município de Prainha hoje conta com 59 parques eólicos distribuídos em 14 municípios, onde a produção de mais de $1 \mathrm{GW}$ de potência eólica é suficiente para abastecer quase 3 milhões de domicílios.

Essa fonte limpa vem gerando emprego e segurança ao setor energético, pois em períodos de estiagem como o que está ocorrendo no corrente ano às fontes renováveis como a eólica assumem importante responsabilidade. As hidrelétricas estão funcionando abaixo do nível o que preocupa a população, o que tranquiliza é saber que temos uma fonte que pode suprir essa falta.

Percebe-se que desde sua implantação dos parques eólicos o estado se tornou um importante produtor e impôs confiança a matriz energética. O Ceará é o estado que dentro de 15 anos passou de 15 MW em 1999 para mais de $1 \mathrm{GW}$ em 2015, graças a seu clima e bons ventos.

A boa localização do estado no território nacional 


\section{POTÊNCIA EÓLICA INSTALADA NO ESTADO DO CEARÁ E IMPACTO EM SUA MATRIZ ENERGÉTICA}

assegurou o funcionamento dos atuais 59 parques eólicos e sua importância ao setor energético. Se a implantação de parques eólicos continuarem aumentando no estado, a energia eólica conseguirá aumentar sua participação na matriz energética e assim diminuir as agressões ao meio ambiente.

Portanto, o presente trabalho tem por objetivo geral identificar o crescimento da potencia eólica instalada no Ceará, desde seus primórdios até os dias atuais. Analisar o crescimento do estado no tocante à implantação de parques eólicos e impactos na matriz energética do mesmo. A partir de um breve histórico da energia eólica no país e descrevendo informações sobre os parques eólicos no Ceará e o crescimento de potencia eólica instalada desde a primeira torre implantada no estado.

\section{HISTÓRICO DA ENERGIA EÓLICA NO BRA- SIL}

O vento (deslocamento das massas de ar) é usado desde a antiguidade. Antes de Cristo os egípcios foram os primeiros a utiliza-lo seguido pelos persas para realização de atividades como moagem de grãos. Segundo a Agência Nacional de Energia Elétrica (ANEEL) a primeira turbina eólica ligada à rede elétrica foi instalada em 1976 na Dinamarca.

No Brasil, a primeira turbina de energia eólica foi instalada em Fernando de Noronha em 1992. No ano de 2000 uma grande seca diminui o nível de água provocando a escassez de energia, prejudicando a economia do país e nos levando a pensar em novas fontes de energia.

Assim no ano de 2002, o Programa de Incentivo às Fontes alternativas de Energia Elétrica (PROINFA) foi criado pelo Ministério de Minas e Energia (MME), com o objetivo de aumentar a participação da energia elétrica produzida através da energia eólica, biomassa e pequenas centrais hidrelétricas.

O PROINFA é considerado o maior programa brasileiro de incentivo as fontes de energia elétrica e tem por intuito promover a diversificação da Matriz Energética, buscando alternativas para aumentar a segurança no abastecimento de energia elétrica, além disso, permitir a valorização das características e potencialidades regionais e locais. O programa iniciou suas atividades prevendo a implantação de 144 usinas, totalizando 3.299,40 MW de capacidade instalada, sendo 1.422, 92 MW provenientes de 54 usinas eólicas. Com o apoio do PROINFA o Brasil descobriu sua vocação para a produção de energias alternativas.

O primeiro leilão de energia eólica foi realizado em 2009, o Brasil realizou o mesmo com o intuito de diversificar sua matriz energética. A cada leilão realizado o país modifica sua matriz energética com o uso de uma porcentagem maior de energias limpas. A região Nordeste sempre marcou presença na geração eólica, com cinco estados contendo parques eólicos em funcionamento, sendo que nesse mesmo ano, o território nacional contava com 36 parques eólicos.

Segundo a Associação Brasileira de Produtores Independentes de energia Elétrica (APINE), o Brasil atingiu em maio de 2012 pela primeira vez $1 \mathrm{GW}$ de energia eólica, marca que torna essa produção renovável responsável por aproximadamente $1 \%$ da matriz energética brasileira, conforme dados da Agência Nacional de Energia Elétrica (ANEEL).

Segundo o Programa de Aceleração do Crescimento (PAC) o potencial de energia eólica em nosso país atingiu em 2013 a $15^{\mathrm{a}}$ posição no ranking mundial, com esses resultados o país chegará em 2015 a $7^{\mathrm{a}}$ posição. Prevendo uma expansão de $6 \mathrm{GW}$ de capacidade instalada de energia eólica em 2015 o Brasil passará a ocupar a segunda posição no ranking de expansão de energia eólica no mundo, ficando atrás da China e superando a Alemanha, país que ocupava essa posição em 2013.

Na Figura 11 é possível observar que o potencial energético do Brasil entre os anos de 1999 a 2013 não parou de crescer. Sendo perceptível que o crescimento anual de potência eólica instalada no país apresentou um aumento significativo a partir do ano de 2006, é notável que desde 2008, quando o país tinha 17 usinas em operação, o potencial energético não parou de crescer.

Segundo a Empresa de Pesquisas Energéticas (EPE) o Balanço Energético Nacional (BEN) do ano de 2014 mostra que a geração de energia eólica cresceu 30,3\% de 2012 a 2013. Cabe ressaltar que a maior parte da energia dos ventos é gerada na região nordeste.

No ano de 2014 a CCEE apontou o Ceará como responsável por $34 \%$ da geração eólica no mês de janeiro. A Agência Nacional de Energia Elétrica (ANEEL) exibiu dados atualizados no último mês de 2014, informando que a matriz energética do Brasil apresentou 228 usinas eólicas em operação das quais o estado do Ceará apresenta 59 em seu território.

A estação chuvosa do Ceará ocorre nos primeiros seis meses do ano, onde os ventos não atingem o número apresentado acima. Observa-se que são inúmeras as condições que favorecem o crescimento dessa energia renovável no estado, dentre elas localização geográfica privilegiada com uma ampla faixa litorânea, baixa turbulência e alta persistência de direção no quadrante nordeste/sul. Ainda segundo analise do Centro Brasileiro de Energia Eólica (CBEE) em todo o litoral cearense a incidência de ventos com uma média anual de velocidade entre 8 e $10 \mathrm{~m} / \mathrm{s}$. 


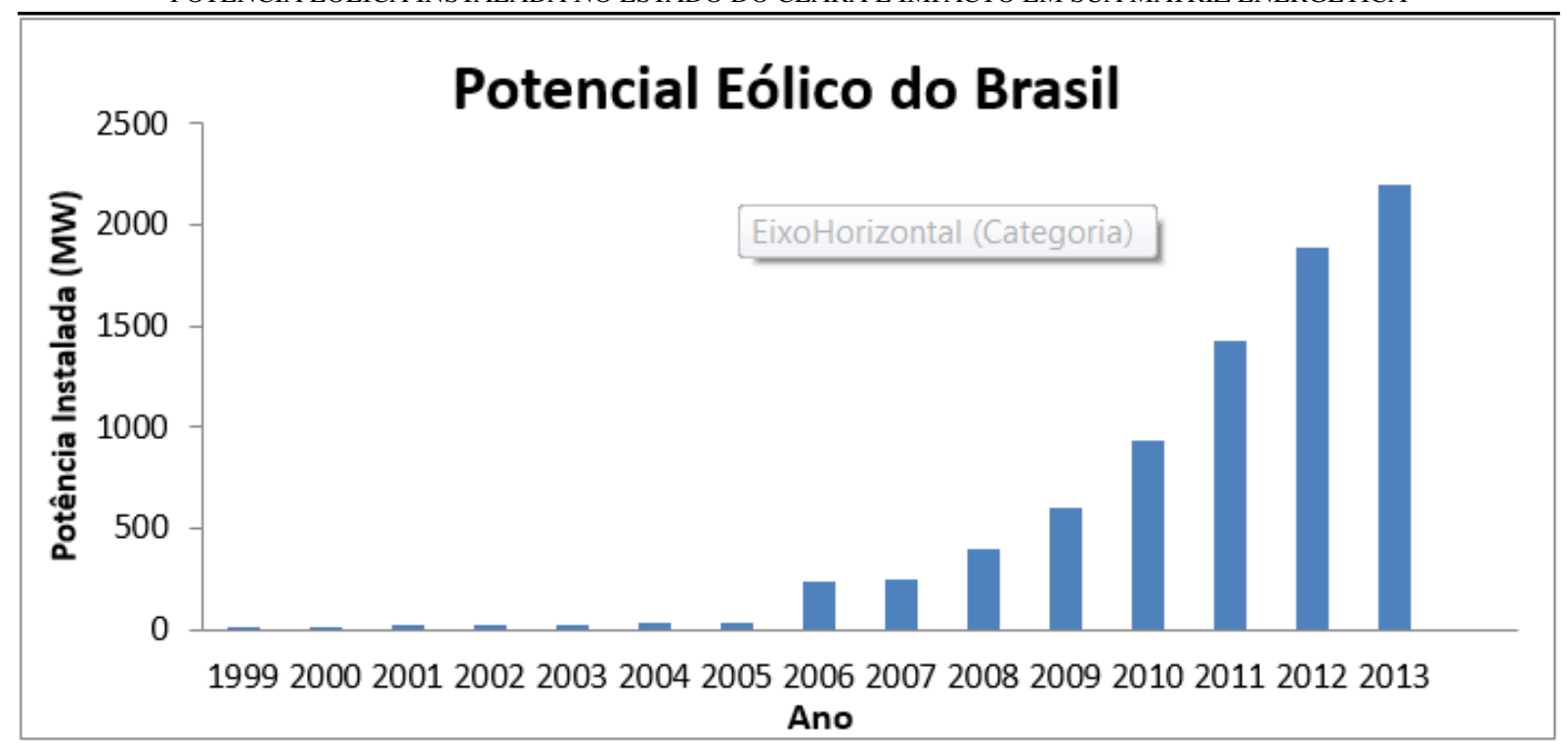

Figura 1: Crescimento anual de Potência instalada no Brasil. Fonte: ANEEL, ABEEOLICA, CCEE, CERNE.

Todos os estados da região nordeste apresentam características em comum uns com os outros com relação a ambiente favorável a produção eólica. A Figura 2 apresenta um gráfico o qual mostra quais são os meses que coincidem com a estação seca na região.

Observamos na Figura 2 que o maior potencial de energia eólica ocorre durante a estação seca a qual coincide com os meses de junho a dezembro. Ainda é possível analisar na imagem que os ventos do litoral atingem valores maiores que o fluxo de água do Rio São Francisco e os ventos do interior do país. Assim, podemos inferir que por essa razão o Ceará vem aumentando seu potencial eólico instalado e se tornando um dos principais estados a buscarem fontes de energias renováveis. Além disso, os longos períodos de estiagem no estado contribuem no aumento do potencial eólico cearense.

\section{USINAS DO CEARÁ}

O Ceará é conhecido por seu vasto litoral e rico panorama ambiental, com o maior número de parques eólicos em funcionamento, sendo o segundo no ranking nacional de geração eólica, perdendo a primeira colocação para o Rio Grande do Norte em abril de 2014. Segundo a Agência Nacional de Energia Elétrica (ANEEL) em janeiro de 1999 o Ceará implantou a primeira Central Eólica, localizada no município de São Gonçalo do Amarante, pioneira em atuar como produtora independente no país. A Central Eólica de Taíba com $5 \mathrm{MW}$ de potência instalada, conta com 10 turbinas de $500 \mathrm{~kW}$. É a primeira usina eólico-elétrica no mundo construída sobre dunas de areia, produzindo mais de 17 milhões de $\mathrm{kW}$ por ano suficiente para atender necessidades domiciliares de 50 mil pessoas.

Após a implantação e funcionamento das primeiras centrais eólicas o estado passou a aumentar anualmente sua potencia eólica. Com 59 usinas eólicas instaladas no Ceará, torna-se necessário importante conhecer o quanto de potencia eólica é produzida anualmente no estado. Assim, na Figura 3 observa-se que a cada ano a potencia instalada aumenta, devido anualmente novas usinas entrarem em funcionamento no estado.

Com o potencial eólico cearense aumentando a cada ano, o estado contribui para o barateamento da energia eólica em leilões, onde dessa maneira mais energias alternativas são inseridas no setor energético estadual e nacional.

A Figura 3 apresenta o potencial eólico anual do estado do Ceará destacando os anos em que a potencia instalada em MW atribuiu ao estado uma colocação importante na posição nacional de geração eólica.

Segundo o Centro de Estratégias em Recursos Naturais e Energia (CERNE), em abril de 2014, o estado perdeu a primeira posição para o Rio Grande do Norte que atingiu $1 \mathrm{GW}$ de potencia com 42 parques eólicos em funcionamento, enquanto o Ceará na mesma data apresentava 39.

$\mathrm{O}$ estado apresenta em sua matriz energética mais de $32 \%$ de energia eólica, o que demonstra que o crescimento dessa fonte renovável é cada vez mais visível e necessário ao país que ultimamente vem enfrentando 
Vazão do Rio Săo Francisco

Vento típico do interior

\section{Vento típico} do litoral

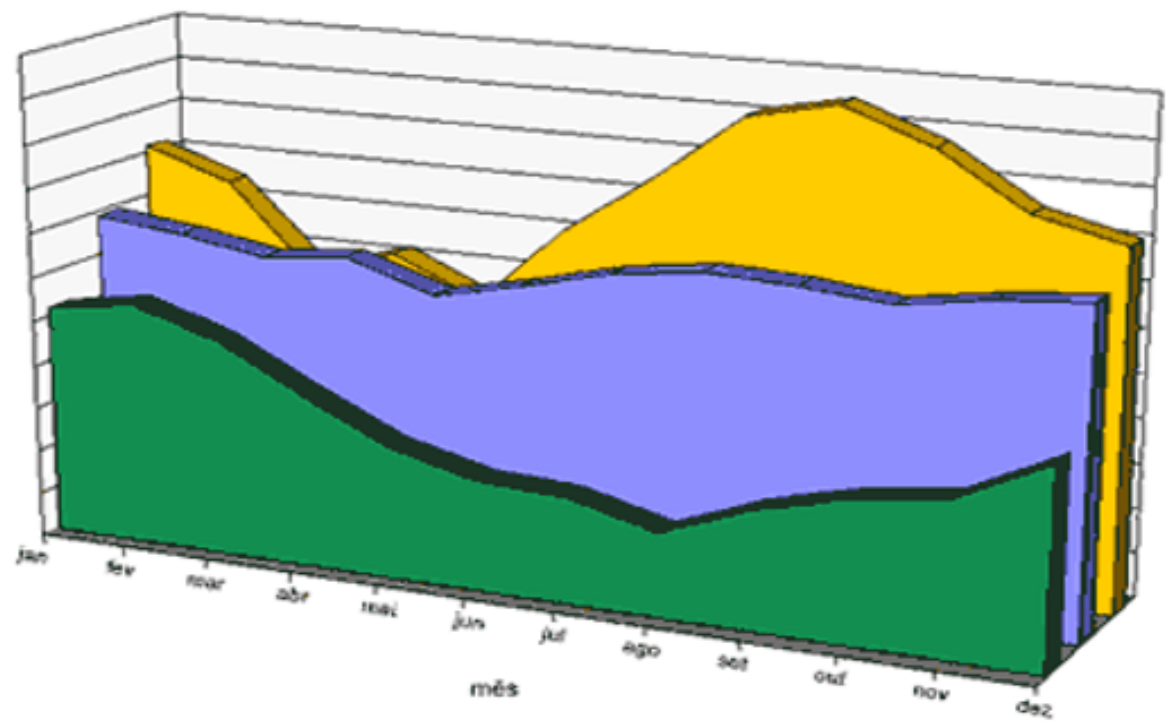

Figura 2: Comparação entre o fluxo de água do Rio São Francisco e o regime de vento no nordeste do Brasil

Fonte CENTRO BRASILEIRO DE ENERGIA EOLICA-CBEE/UFPE.2000. Disponível em: <www.eolica.com.br> (Acessado em 23/12/2014)

\section{POTÊNCIA INSTALADA NO CEARÁ (MW)}

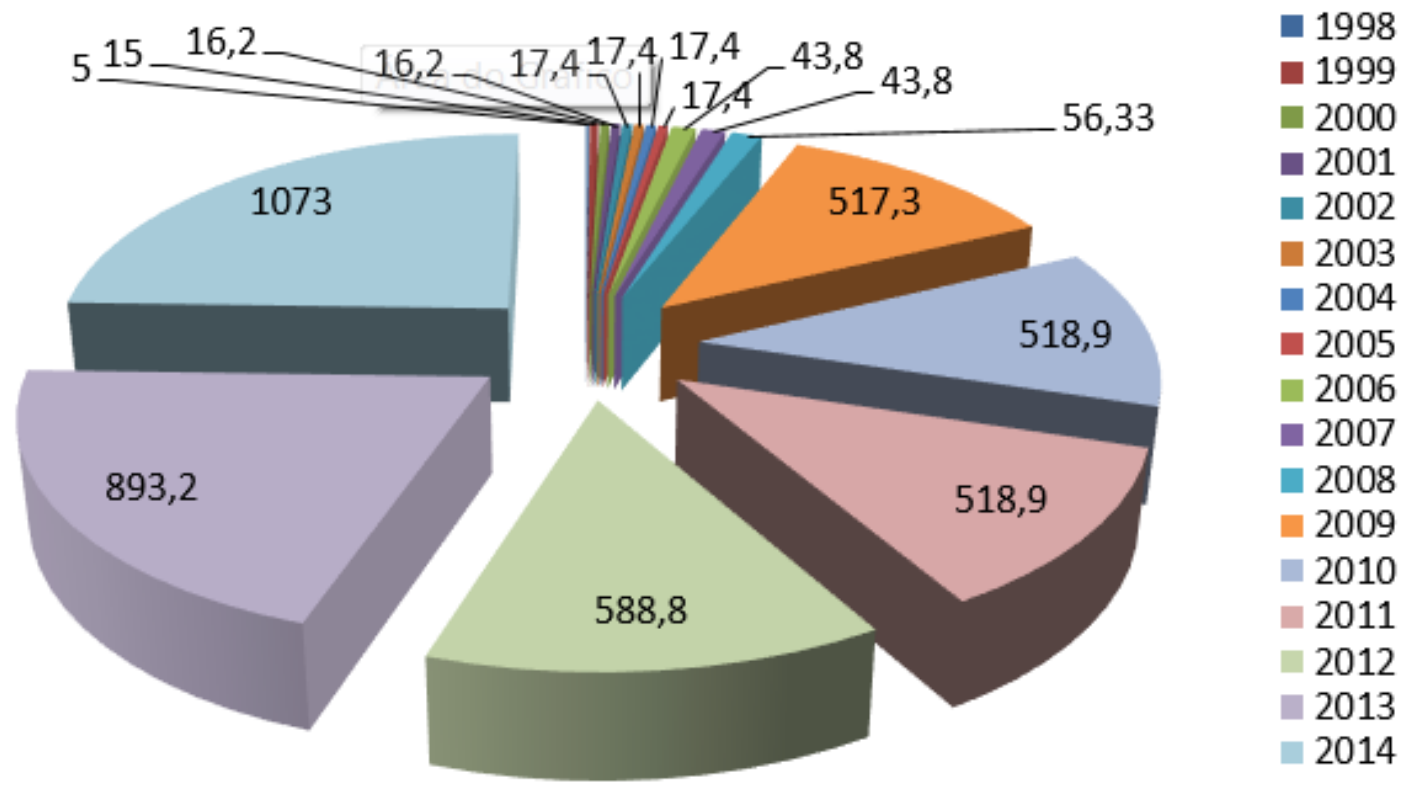

Figura 3: Potencial eólico anual do estado do Ceará. Fonte: ANEEL, ABEEOLICA, CERNE 


\section{POTÊNCIA EÓLICA INSTALADA NO ESTADO DO CEARÁ E IMPACTO EM SUA MATRIZ ENERGÉTICA}

racionamento de água em vários estados.

\section{METOLOGIA}

O desenvolvimento do artigo tem como base o trabalho documental, baseado em estudos e pesquisas a respeito do potencial eólico nacional e no estado do Ceará com maior foco no crescimento energético eólico no estado. As informações apresentadas no corpo do trabalho foram apresentadas por órgãos nacionais que visam integrar um desenvolvimento sustentável ao crescimento mundial. Os dados foram pesquisados e analisados antes de serem apresentados. A maioria das informações pode ser encontrada em páginas on-line que apresentam dados cedidos pela ANEEL, o PROINFA, a CERNE, a CCEE, entre outras empresas.

A partir de dados cedidos por essas empresas a sites de informação que podem ser confirmados em páginas das empresas citadas anteriormente, em artigos, em pesquisas realizadas por profissionais que estudam essa fonte renovável, é possível visualizar elementos muitas vezes desconhecidos pela sociedade em geral.

Será observado o impacto na matriz energética no âmbito nacional e estadual desde a implantação da primeira usina eólica no Ceará até os dias atuais, analisando ano por ano por meio de figuras onde os dados são apresentados.

\section{RESULTADOS}

Após analisar dados e informações de órgãos responsáveis pela divulgação de números mensais e anuais com relação à produção eólica no Brasil e principalmente no estado do Ceará, percebe-se o crescimento em grande escala dessa fonte renovável e a importância do planejamento energético, observa-se que a ferramenta pode suprir as necessidades elétricas e gerar renda ao estado.

Nas Figuras 4 e 5 podemos observar o desenvolvimento da implantação de usinas eólicas no Ceará, as imagens exibem dados de 1999 e junho de 2014.

As Figuras 4 e 5 apresentam o crescimento da energia eólica no país e principalmente no Ceará, onde é visível que do ano de 1999 até junho de 2014, o estado colocou em operação mais de 12 vezes a quantidade de centrais e parques eólicos. Verifica-se que em 1999 o estado apresentava somente três setores eólicos em operação e em 2014 são trinta e oito os parques eólicos em funcionamento.

Atualmente o estado conta com 59 parques eólicos em funcionamento distribuídos em 14 municípios produzindo mais de $57 \%$ da energia consumida no estado. Com essa porcentagem de produção eólica inserida na matriz energética cearense, o estado é capaz de suprir as necessidades de quase 3 milhões de residências.

A Figura 6 mostra a localização dos novos parques eólicos por município e a quantidade de potência eólica produzida por cada um, além de apresentar o total em GW e quanto de domicílios essa produção pode prover.

A Figura 6 mostra que quando o Ceará atingir 1,23 GW de potência eólica o estado pode abastecer 2,9 milhões de domicílios. $\mathrm{O}$ estado atualmente expressa uma produção de mais de $1 \mathrm{GW}$ equivalente a mais de $57 \%$ de toda a energia consumida no estado. Observa-se que em 2013 o estado apresentava uma produção eólica de quase $600 \mathrm{MW}$ que significava $32 \%$ de eólica inserida na matriz energética estadual.

A Tabela 1 exibe todos os parques eólicos em operação no estado do Ceará e a potência eólica de cada um, além de expor os municípios em que os mesmos estão situados.

A Tabela 1 apresenta todos os Parques Eólicos em operação no estado do Ceará, desde seus primórdios até os dias atuais do ano de 2015. E verídico que a implantação desses parques ocorreu em diferentes municípios, o que propicia um crescimento financeiro aos mesmos e torna-os responsáveis pela implantação de energia limpa na matriz energética do estado.

O município que apresenta o maior número de parques eólicos em seu território é o de Trairi com 13 parques eólicos em sua extensão territorial, seguido da capital Fortaleza com 10 parques em seu território. Segundo dados da Agência Nacional de Energia Elétrica (ANEEL), o estado do Ceará apresenta 59 parques eólicos onde mais de $60 \%$ deles entraram em operação a partir de 2013.

Nos últimos anos o estado vem ampliando o setor energético eólico com a construção de novos parques eólicos. Esse crescimento acaba por gerar uma série de discursões a respeito do assunto, pois muitos ambientalistas defendem a ideia de que o funcionamento desses parques eólicos acarreta danos ao meio ambiente e as belezas naturais do estado.

Devido a essas discursões cada vez mais há uma preocupação com relação à implantação de parques eólicos, mais vale ressaltar que antes das mesmas ocorrerem, é realizado estudos e analises por parte das empresas responsáveis. Com isso, só ocorre implantação de parques eólicos em locais em que os danos à natureza e a população são minúsculos além de gerar benefícios sociais e econômicos.

É visível que a região nordeste é maior produtora no ramo eólico, devido sua proximidade com a faixa litorânea. No estado do Ceará anualmente a velocidade dos ventos atinge em relação ao solo valores superiores 


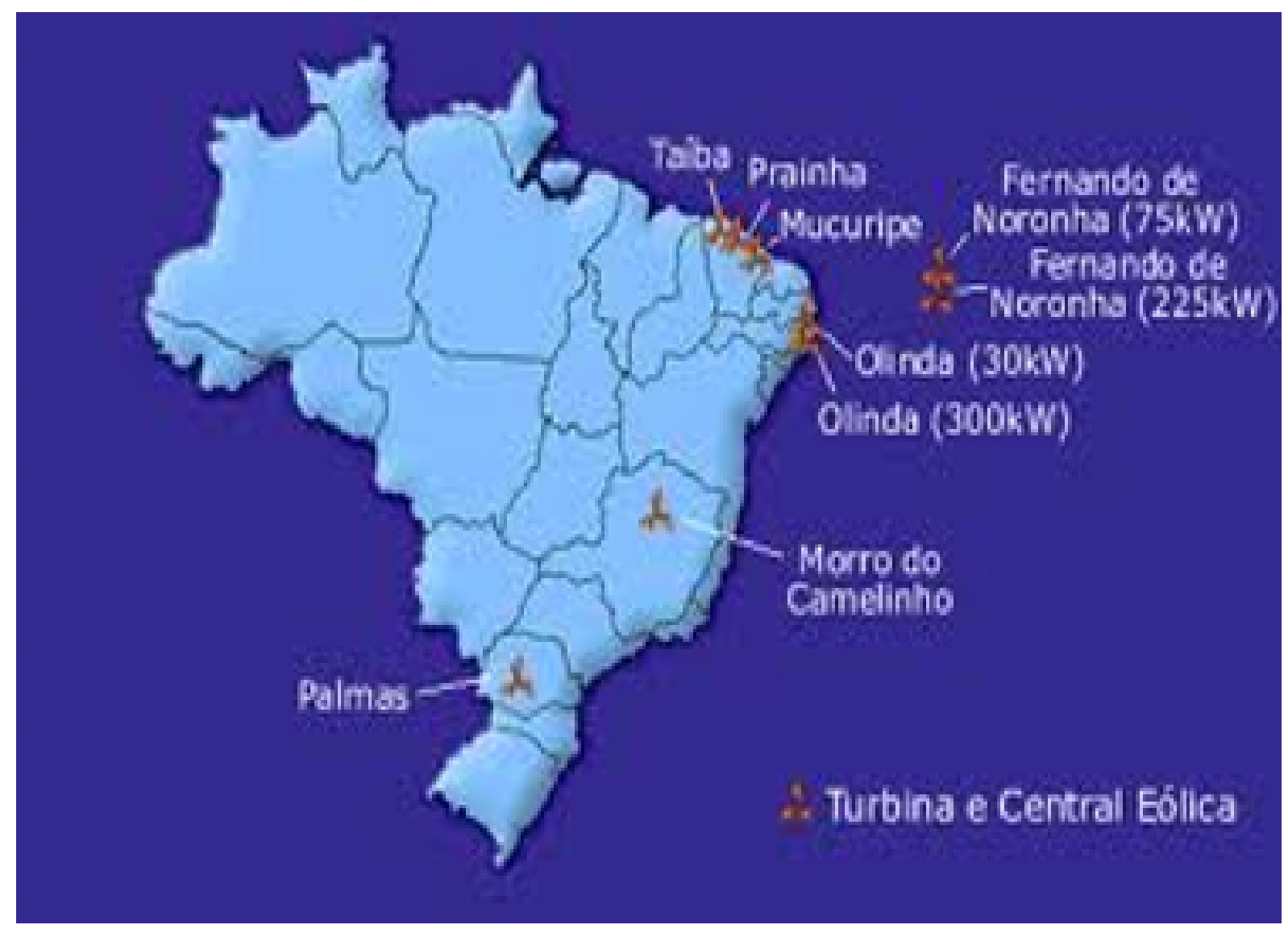

Figura 4: Mapa das Turbinas e Centrais eólicas em Funcionamento em 1999. Fonte: Google imagens. Disponível em: www.eolica.com.br (Acessado em 12/10/2014) 


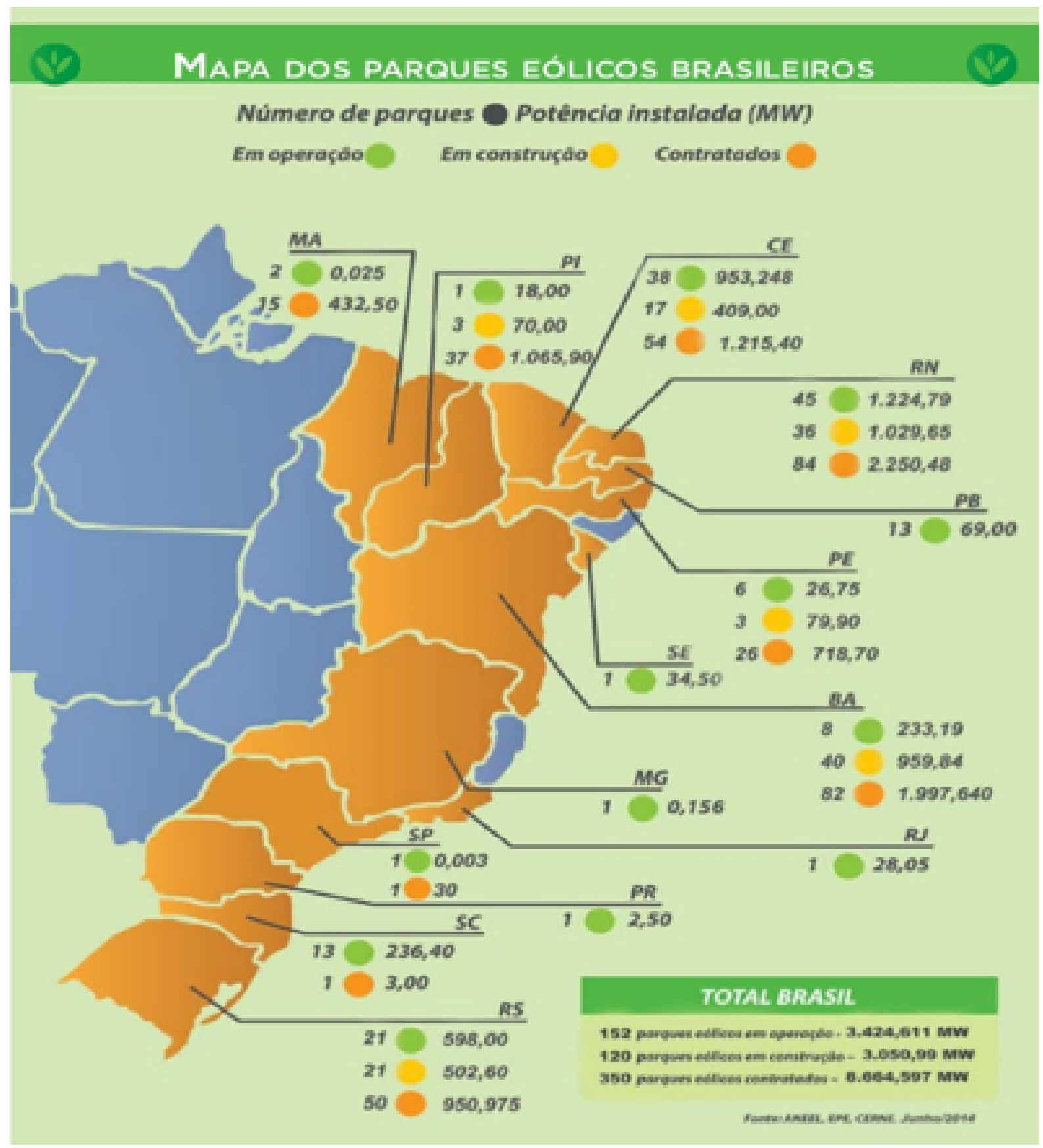

Figura 5: Mapa dos Parques Eólicos Brasileiros. Fonte: ANEEL, EPE, CERNE, junho 2014. 


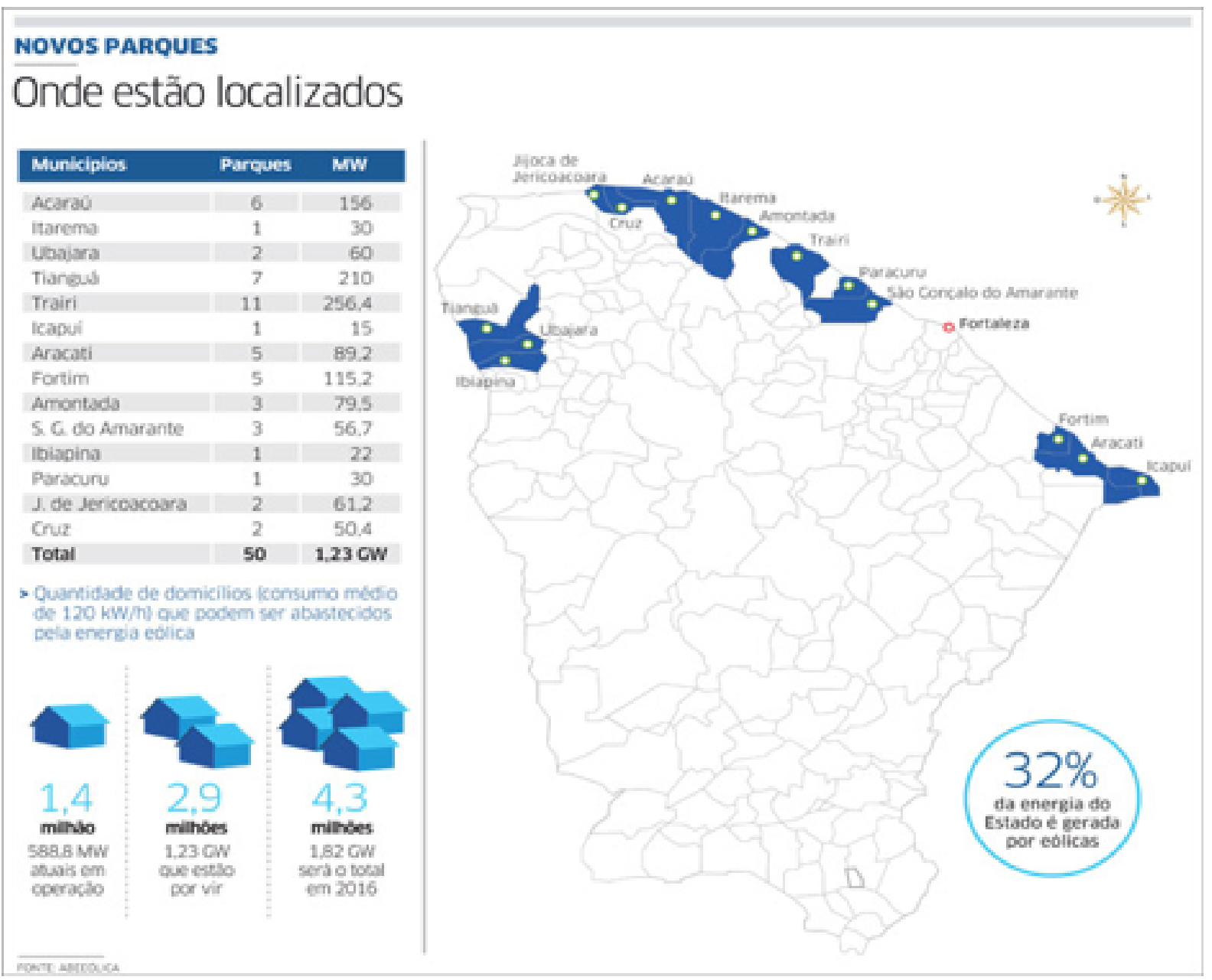

Figura 6: Número de parques eólicos por município no estado do Ceará. Fonte: Abeeólica. 
Tabela 1: Parques Eólicos em Operação no Ceará desde 1998 a 2015

\begin{tabular}{|c|c|c|}
\hline \multicolumn{3}{|c|}{ PARQUES EÓLICOS EM OPERAÇÃO NO CEARÁ } \\
\hline USINA & $\begin{array}{l}\text { POTÊNCIA } \\
\text { (KW) }\end{array}$ & MUNICÍPIO \\
\hline Eólica de Taíba & 5.000 & Aquiraz \\
\hline Eólica de Prainha & 10.000 & São Gonçalo do Amarante \\
\hline Mucuripe & 2.400 & Fortaleza \\
\hline Parque Eólico de Beberibe & 25.600 & Beberibe \\
\hline Praia do Morgado & 28.800 & Acaraú \\
\hline Volta do Rio & 42.000 & Acaraú \\
\hline Foz do Rio Choró & 25.200 & Beberibe \\
\hline Praia Formosa & 104.400 & Camocim \\
\hline Eólica Canoa quebrada & 10.500 & Aracati \\
\hline Lagoa do Mato & 3.230 & Aracati \\
\hline Eólica Icaraizinho & 54.600 & Amontada \\
\hline Eólica Paracuru & 23.400 & Paracuru \\
\hline Eólica Praias de Parajuru & 28.804 & Beberibe \\
\hline Parque Eólico Enacel & 31.500 & Aracati \\
\hline Canoa Quebrada & 57.000 & Aracati \\
\hline Taiba Albatroz & 16.500 & São Gonçalo do Amarante \\
\hline Bons Ventos & 50.000 & Aracati \\
\hline Quixaba & 25.500 & Aracati \\
\hline Trairí & 25.388 & Trairi \\
\hline Cajucoco & 30.000 & Itarema \\
\hline Guajirú & 30.004 & Trairi \\
\hline Taíba Águia & 23.100 & São Gonçalo do Amarante \\
\hline Buriti & 30.000 & Acaraú \\
\hline Coqueiros & 15.000 & Acaraú \\
\hline Icaraí & 16.800 & Amontada \\
\hline Colônia & 18.900 & São Gonçalo do Amarante \\
\hline Dunas do Paracuru & 42.000 & Paracuru \\
\hline Faísa I & 29.400 & Trairi \\
\hline Faísa II & 27.300 & Trairi \\
\hline Faísa III & 25.200 & Trairi \\
\hline Faísa IV & 25.200 & Trairi \\
\hline Faísa V & 29.400 & Trairi \\
\hline Embuaca & 27.300 & Trairi \\
\hline Icaraì I & 27.300 & Amontada \\
\hline Icarai II & 37.800 & Amontada \\
\hline Taíba Andorinha & 14.700 & São Gonçalo do Amarante \\
\hline Mundaú & 30.004 & Trairi \\
\hline Fleixeiras I & 30.004 & Trairi \\
\hline Ilha Grande & 29.700 & Amontada \\
\hline Ribeirão & 21.600 & Amontada \\
\hline Boca do Córrego & 24.300 & Amontada \\
\hline São Jorge & 24.000 & Trairi \\
\hline São Cristovão & 26.000 & Trairi \\
\hline Santo Antônio de Pádua & 14.000 & Trairi \\
\hline Antônio Augusto Pimentel de Sousa & 2 & Fortaleza \\
\hline Geraldo Júnior Cavalcante Lopes & 2 & Fortaleza \\
\hline Pedro Pedron & 2 & Eusébio \\
\hline Stela Maris Zambelli & 2 & Eusébio \\
\hline Tarlene Guedes Bessa & 2 & Fortaleza \\
\hline Satrix & 5 & Eusébio \\
\hline Valberto Barbosa Porto Filho & 4 & Fortaleza \\
\hline Eco Sistema de Paisagismo & 4 & Aquiraz \\
\hline Jacob Benvindo & 4 & Fortaleza \\
\hline Vanda Lúcia Tomaz Lima & 2 & Fortaleza \\
\hline Nogueira de Morais & 1 & Fortaleza \\
\hline Caio César Bianchi & 4 & Fortaleza \\
\hline Dulio César Bianchi & 4 & Fortaleza \\
\hline Construtora Nogueira de Morais & 1 & Fortaleza \\
\hline $\begin{array}{l}\text { Autarquia Municipal de Meio } \\
\text { Ambiente }\end{array}$ & 4 & Eusébio \\
\hline
\end{tabular}

Fonte - Agência Nacional de Energia Elétrica - ANEEL (2015) 


\section{POTÊNCIA EÓLICA INSTALADA NO ESTADO DO CEARÁ E IMPACTO EM SUA MATRIZ ENERGÉTICA}

a $7,5 \mathrm{~m} / \mathrm{s}$ a uma altura de 50 metros.

A Figura 6 apresenta o mapa do Brasil separado por regiões, determinando o quanto de potencia eólica cada região pode gerar.

Na Figura 7 é perceptível que à região Nordeste sozinha, pode gerar de potencial eólico muito mais que as demais regiões do país. No ano de 2014 dois estados do Nordeste atingiram $1 \mathrm{GW}$ de potencia instalada, os mesmos são Rio Grande do Norte e Ceará.

\section{CONCLUSÃO:}

O Brasil é conhecido por sua extensa faixa litorânea, tendo implantado 241 parques eólicos em seu território o país passa a introduzir em sua matriz energética cerca de 4,5\% de energia eólica. O mesmo vem conseguindo esses valores graças à criação de programas de incentivo a produção renovável como é o caso do PROINFA criado em 2001.

A energia eólica é um exemplo de energia limpa que vem dando certo no Ceará e ajudando as comunidades locais a ampliar a economia. O Ceará é um dos estados com maior potencial eólico instalado, onde essa marca deve-se ao fato do número de parques eólicos em funcionamento. Estima-se que o potencial eólico cearense aumentará nos próximos anos, pois vários projetos de implantação de parques eólicos encontram-se em andamento.

Os dados coletados mostram que a cada ano o estado vem ampliando o potencial eólico e inserindo cada vez mais uma porcentagem maior de energia eólica na matriz energética estadual, assim como na nacional. Com essas análises é possível prever que futuramente o Ceará continuará sendo um dos maiores produtores de energia eólica no país, auxiliando o setor energético no uso de energias provindas de fontes limpas.

Com esse crescimento de potencial eólico o preço da eólica em leilões nacionais vai ficar mais acessível, propiciando um uso maior dessa fonte alternativa de energia. Cabe ressaltar que a cada ano mais parques eólicos são instalados o que garante que a energia proveniente dos ventos seja cada vez mais utilizada. Além disso, os longos períodos de estiagem tem valor significativo nesse aumento.

Portanto, são de grande importância as fontes limpas de energia e o setor eólico tem valor significativo no estado do Ceará e no país, devido ser uma fonte alternativa, que a cada leilão energético busca um melhor serviço e diminuição do valor dessa energia renovável. Com certeza a situação ambiental ganhou uma grande aliada, onde se é possível estimar que a mesma só tem a crescer.
Conclui-se que o estado além de ser segundo no ranking de produção eólica nacional, é um dos responsáveis pelo aumento de potencial eólico inserido na matriz energética do país. Com isso, também passa a inserir mais de $57 \%$ de eólica na matriz estadual aumentando a segurança energética e mostrando ao mundo que estamos preocupados com a situação ambiental atual.

\section{REFERÊNCIAS}

ABEEOLICA, P. Com a força dos ventos a gente vai mais longe. Disponível em: $<$ http://www.portalabeeolica.org.br/index.php/noticias/ 2079-os-rumos-da-energia-e\% C3\%B3lica-no-cear\% C3\%A1.html> Acesso em: 25 out. 2014.

ANEEL. Energia Eólica. Disponível em: <http://www.aneel.gov.br/aplicacoes/atlas/pdf/ 06-energia_eolica(3).pdf $>$ Acesso em: 9 set. 2014.

Matriz energética do Brasil. Disponível em: <http://www.aneel.gov.br/aplicacoes/ capacidadebrasil/OperacaoGeracaoTipo.asp?tipo=7\& ger=Combustivel\&principal=E\%F3lica $>$ Acesso em: 4 jun. 2015.

CARVALHO, I. V.; MESQUITA, A. L.; SANTOS, P. G. de L.; SANTOS, J. S. Densidade de potencial eólico nas diferentes regiões do estado do ceará - litoral, serra e sertão: a climatologia e as novas tecnologias. Revista Geonorte, Edição especial 2, v. 2, n. 5, p. 1317-1327, 2012.

CCEE. Boletim das usinas eólicas. Disponível em: <http://www.ccee.org.br/ccee/documentos/CCEE_ 204801>. Acesso em: 14 abr. 2015.

CEPEL. Atlas do potencial eólico do Brasil. Disponível em: <http://www.cresesb.cepel.br/publicacoes> Acesso em: 19 dez. 2014.

CERNE. RN quebra a barreira de $1 \mathrm{GW} e$ lidera ranking eólico no Brasil. Disponível em: <http://www.cerne.org.br/pt-BR/noticias/ rn-quebra-a-barreira-de-1-gw-e-lidera-ranking-eolico-no-brasil> Acesso em: 10 jun. 2014.

CUSTÓDIO, R. dos S. A energia eólica e o meio ambiente. In: CUSTÓDIO, R. dos S. (Ed.). Energia eólica para a produção de energia elétrica. 1. ed. Rio de Janeiro: Centro da Memória da Eletricidade no Brasil, Memória da Eletricidade, 2009.

EPE. Balanço Energético Nacional. Disponível em: $<$ https://ben.epe.gov.br/downloads/Relatorio_Final_ BEN_2014.pdf> Acesso em: 20 maio 2015. 


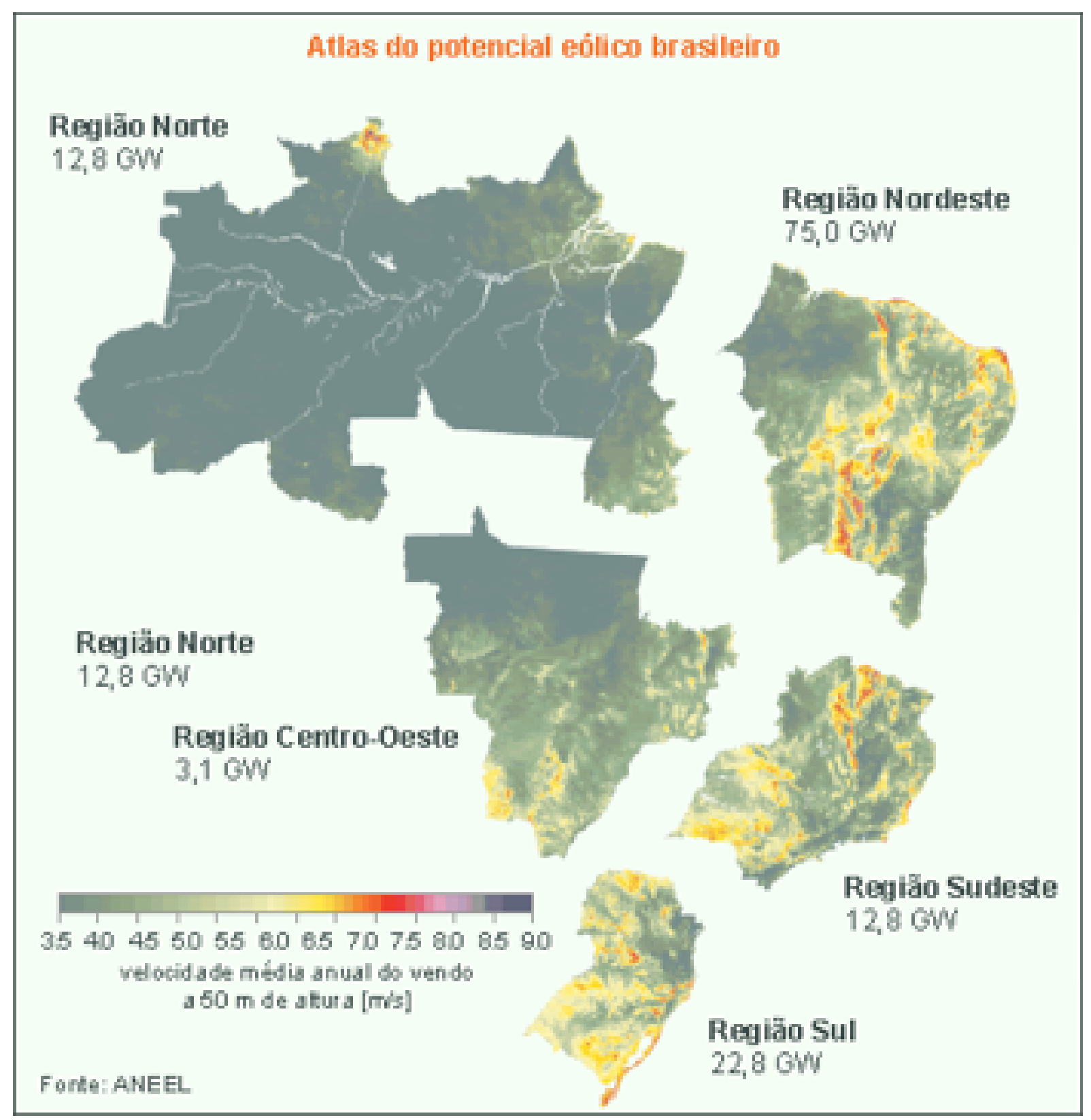

Figura 7: Atlas do Potencial Eólico do Brasil. Fonte: http://www.cresesb.cepel.br/publicacoes. (Acessado em 19/12/2014). 
FREITAS, R. J. N. Energia eólica: Os conflitos sócio ambientais gerados pela implantação dos parques eólicos no litoral do Ceará. 2014. Disponível em: <http://www.anppas.org.br/encontro6/anais/ ARQUIVOS/GT17-899-662-20120630234422.pdf> Acesso em: 15 nov. 2014.

GOOGLE. Imagens de mapas das centrais eólicas do Brasil. Disponível em: <https: //www.google.com.br/search?q=imagens+de+mapas+ das+centrais+eolicas+no+brasil> Acesso em: 9 abr. 2015.

PLANEJAMENTO, P. M. do. Brasil ultrapassa Alemanha em expansão de energia eólica em 2015. Disponível em: <http://www.pac.gov.br/noticia/ 22d0c0bd> Acesso em: 17 maio 2015.

Brasil é o $4^{o}$ produtor de energia eólica no mundo. Disponível em: <http: //www.pac.gov.br/noticia/3c67e495> Acesso em: 14 set. 2014.

SILVA, J. J. L. A gestão ambiental e a sustentabilidade no setor de energia eólica no Ceará. Fortaleza, 2013. Disponível em: $<$ http://www.faculdadescearenses.edu.br/biblioteca/ TCC/ADM/A\%20GESTAO\%20AMBIENTAL\% 20E\%20A\%20SUSTENTABILIDADE\%20NO\% 20SETOR\%20DE\%20ENERGIA.pdf> Acesso em: 16 nov. 2014. 